\title{
The Effects of Service Quality on Satisfaction and Purchase Intention in Mobile Commerce
}

\author{
Nur Ain Mohd Paiz ${ }^{1}$, Mass Hareeza Ali ${ }^{1}$, Abdul Rashid Abdullah ${ }^{1} \&$ Zuraina Dato Mansor ${ }^{1}$ \\ ${ }^{1}$ Faculty of Economics and Management, Department of Management and Marketing, Universiti Putra Malaysia, \\ Selangor, Malaysia \\ Correspondence: Nur Ain Mohd Paiz, Faculty of Economics and Management, Department of Management and \\ Marketing, Universiti Putra Malaysia, Selangor, Malaysia. E-mail: aienpaiz@gmail.com
}

Received: September 10, 2019

Accepted: January 22, 2020

Online Published: March 9, 2020

doi:10.5539/ijbm.v15n4p36

URL: https://doi.org/10.5539/ijbm.v15n4p36

\begin{abstract}
The purpose of this study is to investigate the effect of service quality on the relationship between mobile shoppers' satisfaction and purchase intention towards mobile commerce. The survey method was conducted with a structured questionnaire that was distributed to 385 mobile users in Malaysia which tested against a proposed model using partial least square structural equation modelling. The result confirms service quality affects mobile shoppers' satisfaction and purchase intention directly. Furthermore, the result also affirms that mobile shoppers' satisfaction mediates the relationship between service quality and purchase intention. This study will assist the mobile commerce industry to understand mobile shoppers' behaviour in Malaysia.
\end{abstract}

Keywords: service quality, customer satisfaction, purchase intention, mobile commerce

\section{Introduction}

The development of mobile device technology has contributed to the growth of mobile commerce, which allows Malaysian consumers to do online shopping via mobile device (MIS Asia, 2017). The high growth in the use of the mobile internet, the increasing number of mobile device users and the popularity of mobile technologies has contributed to the un-precedent growth of mobile commerce in meeting peoples' needs and demands as it allows consumers to shop online at any time and location (Nguyen et al., 2018). Malaysia has emerged as the top two in the Southeast Asia region market in mobile commerce penetration, with 21.62 million active mobile internet users who use the website to search, interact, compare products, read reviews and do online shopping (Ghazali et al., 2018). The total sales of transactions generated by mobile commerce has evolve significantly with 58.5 million in 2017, an increase of $53.1 \%$ in 2016 from 27.4 million in 2016 (Borneo Post, 2018). Currently, the project global mobile commerce is expected to exceed RM4.08 billion in 2018 (The Star, 2016). This makes Malaysia a potential and attractive market for many mobile commerce players. The market size of mobile commerce is boosted by the high penetration rate of the mobile devices in Malaysia. This could also be contributed by users who enjoy immediate purchasing through their own mobile device, as well as the rapid rise in mobile commerce, generating an increase in mobile commerce sales over the next five years. As the popularity and technologies of mobile device progress, mobile commerce acceptance is becoming very apparent. This trend will certainly continue in the near future (Liu et al., 2019).

Many empirical studies have highlighted the interrelationships among the constructs of service quality, customer satisfaction, and purchase intentions in various industries (Paulo et al., 2019; Shrawan \& Mohit, 2018; Mariam et al., 2018; Hussain, 2016). There is evidence that service quality has either a direct or indirect significant association with purchase intention mediated through customer satisfaction (Zeithaml et al., 1996; Cronin et al., 2000). Given these established relationships, it is important for the online retailers to measure and monitor service quality to build customer satisfaction which in turn has a significant influence on consumers' purchase intentions. Although the interrelationships among service quality, customer satisfaction, and purchase intentions are well documented in the classical service literature such relationships have not been fully subjected to conceptual and empirical perspective investigation especially in the mobile commerce context. According to Zeithaml et al. (2002) have urgent future researchers need to pay particular attention to the concept of service quality and its associated consequences in the online environment context.

In light of the preceding discussion, the objective of this research is to contribute to the mobile commerce literature 
in a number of ways. Firstly, it investigates the relationship between service quality, customer satisfaction and purchase intention toward mobile commerce. Secondly, the study investigates the mediating effects of customer satisfaction on the relationship between service quality and purchase intention. The rest of this paper is organized as follows. We first develop our literature review, conceptual model and associated research hypotheses that address the relationships among service quality, customer satisfaction, and purchase intention. Then, we describe the research methodology in the study and follow by reporting the data analysis results. Finally, we conclude by discussing managerial implications, limitations and also future research directions.

\section{Literature Review and Research Hypotheses Development}

\subsection{Service Quality (SQ)}

One of the most important factors for the determination of purchase intention is the overall perceived service quality, which will eventually attract more consumers (Spiros, Sergios, \& Vlasis, 2010). Based on Parasuraman et al., (2005), SQ is broadly to encompass all phases of a customer's interaction with a website; the extent to which a website facilitates efficient and effective shopping, purchasing and delivery. There are several instruments to measure SQ such as WebQual, SITE-QUAL, eTailQ, E-S-QUAL, Revised SERVQUAL and e-commerce CPQ. The present study adopts eTailQ model by Wolfinbarger \& Gilly (2003) which consist of website design, reliability/fulfilment, security/privacy, and customer service. eTailQ was selected as model for measurement since it can comprehensively measure SQ especially in mobile commerce. There were existing studies of SQ in the mobile commerce context explored by several researchers (Markus 2016; Markus et al., 2015) mainly focused on the specific dimensions in overall SQ measurement, but not based on the overall study of SQ. This study utilises four dimensions to measure the overall SQ with mobile commerce. Thus, looking at the absence for the study of overall SQ in mobile commerce context, this study aims to bridge the gap and the proposed SQ as the factor that could affect CS and PI towards mobile commerce. A positive and direct impact of SQ on CS and PI is shown in several studies. In the mobile commerce context, Anas et al., (2018) and Sukanya and Saroj (2015) revealed that SQ affects the CS positively and significant relationship. Karin (2019) and Yousef and Dariyoush (2018) found the presence of a significant and positive relationship between SQ and PI.

\subsection{Customer Satisfaction (CS)}

$\mathrm{CS}$ has also been identified as a key variable for generating consumer purchase intention towards a service. Though mobile commerce has penetrated everyday life, CS in mobile commerce has rarely been studied because of its short history (Rakhi, 2018). As at the initiating stage of mobile commerce, most of the researchers paid attention to the customer's intention to accept electronic commerce, rather than CS in mobile commerce. CS is important for establishing long term customer relationships and to further generates PI (Enrique \& Karla, 2019). The definition of CS is the contentment of a consumer concerning to his or her prior purchasing experience (Anderson \& Srinivasan, 2003). However, the relationship between CS and PI is still ambiguous because there are only a few studies that explore how to strengthen it. Thus, the present study intends to fulfil the gap of proposing CS as the outcome of the determinant namely SQ. A positive and direct impact of CS and PI is shown by several studies in mobile commerce context. Paulo et al., (2019) for instance, added that CS has a direct and positive effects on their PI. Mariam et al., (2018) revealed that CS has a significant effect on their purchase intention towards mobile commerce. In addition, Shrawan and Mohit (2018) also found that CS played a critical mediator role between SQ and PI. Therefore, CS plays as a mediating variable between SQ and PI in this study.

\subsection{Purchase Intention (PI)}

PI refers to the probability that an individual will purchase a particular product based on the interaction between customer needs, attitude and perception (Beneke et al., 2016). Purchase intention can be treated as an estimator of consumer behaviour (Wu et al., 2011). It can be considered as consumer's interest to buy specific items (Kamalul Ariffin et al., 2018). In other words, purchase intention determines the strength of consumer willingness to purchase (Lee et al., 2017). It is crucial to recognise consumer's PI because their actions are usually predicted through their intentions (Hsu et al., 2017). There were existing studies found that SQ and CS ultimately determined the consumer's PI, which is an important of actual buying behaviour (Mariam et al., 2018; Shrawan \& Mohit, 2018; Kim, 2016; Shin, 2015). Therefore, the construct of PI is considered as an outcome variable in this study and included as a dependent variable in our model.

\subsection{Conceptual Model and Hypotheses Development}

The aim of this study integrates service quality and purchase intention in one framework for measuring the mediating effects of customer satisfaction. There are three main constructs namely Service Quality (SQ), Customer Satisfaction (CS), and Purchase Intention (PI). SQ was the exogenous construct while CS and PI were the 
endogenous constructs. The following conceptual model (Figure 1) for this study was developed and represent the relationships between the different construct used to the following hypotheses:

HI: There is a significant positive relationship between service quality and customer satisfaction of mobile commerce.

H2: There is a significant positive relationship between service quality and purchase intention of mobile commerce.

H3: There is a significant positive relationship between customer satisfaction and purchase intention of mobile commerce.

H4: Customer satisfaction mediates the relationship between service quality and purchase intention of mobile commerce.

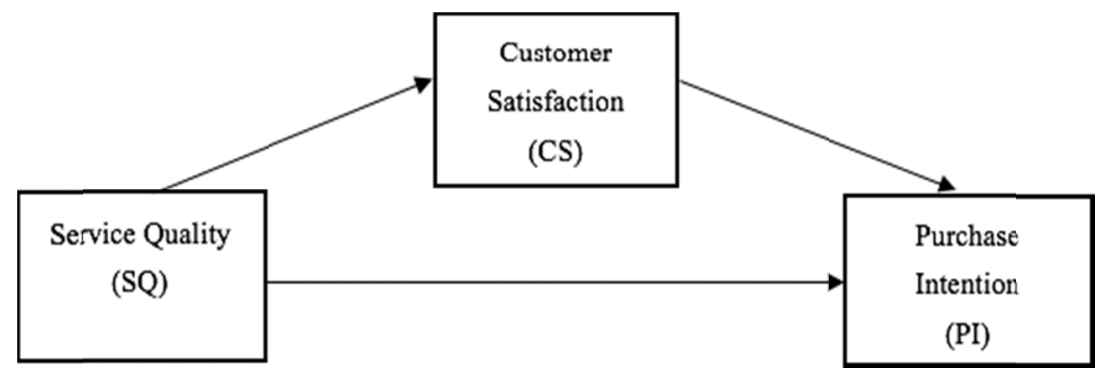

Figure 1. Conceptual model

\section{Research Methodology}

This is a quantitative research whereby a survey questionnaire was used for data collection. The target population of this study is individuals who are mobile device users. The reason why these users were considered was due to the fact that they were considered to be more likely to adopt mobile commerce in the future. The surveys for this study were distributed at mobile service providers shops such as Celcom, Digi and Maxis located in various shopping malls in Malaysia. A sample size of 385 was required based on Krejcie and Morgan's (1970) table. A total of 434 hardcopy questionnaires were distributed. Then, 385 completed questionnaires were used for data analysis using used SmartPLS 3.0 software. As referring to the Partial Least Square-Structural Equation Modelling (PLS-SEM) protocol, two main assessment were conducted, which are the measurement model and structural model (Hair et al., 2017).

\section{Results}

\subsection{Measurement Model Analysis}

Before the hypothesis testing, the measurement model of this study had to be assessed for its convergent and discriminant validity. The measurement model consists of relationships among the latent constructs of interests and the measures (indicators) underlying each construct. Thus, it is important to establish whether the indicators reflect their underlying constructs. Table 1 lists the indicator loadings, average variance extracted (AVE), and composite reliability scores for all the constructs in the measurement model. The result indicates that all constructs confirm the convergent validity with loadings more than 0.7 and the average variance extracted (AVE) of more than 0.5 . 
Table 1. Convergent validity of the measurement model

\begin{tabular}{|c|c|c|c|c|}
\hline Construct & Item & Loadings & $\mathrm{CR}$ & AVE \\
\hline Service Quality & SQ & & 0.854 & 0.593 \\
\hline \multirow[t]{6}{*}{ Website Design } & & & 0.878 & 0.589 \\
\hline & SQA1 & 0.789 & & \\
\hline & SQA2 & 0.740 & & \\
\hline & SQA3 & 0.796 & & \\
\hline & SQA4 & 0.765 & & \\
\hline & SQA5 & 0.748 & & \\
\hline \multirow{6}{*}{$\begin{array}{l}\text { Fulfilment / } \\
\text { Reliability }\end{array}$} & & & 0.861 & 0.608 \\
\hline & & & & \\
\hline & SQB1 & 0.778 & & \\
\hline & SQB2 & 0.783 & & \\
\hline & SQB3 & 0.766 & & \\
\hline & SQB4 & 0.792 & & \\
\hline \multirow{6}{*}{ Security/Privacy } & & & 0.895 & 0.630 \\
\hline & SQC1 & 0.700 & & \\
\hline & SQC2 & 0.776 & & \\
\hline & SQC3 & 0.734 & & \\
\hline & SQC4 & 0.752 & & \\
\hline & SQC5 & 0.720 & & \\
\hline \multirow[t]{6}{*}{ Customer Service } & & & 0.894 & 0.627 \\
\hline & SQD1 & 0.781 & & \\
\hline & SQD2 & 0.820 & & \\
\hline & SQD3 & 0.815 & & \\
\hline & SQD4 & 0.767 & & \\
\hline & SQD5 & 0.776 & & \\
\hline \multirow[t]{6}{*}{ Customer Satisfaction } & & & 0.880 & 0.554 \\
\hline & $\mathrm{CS} 1$ & 0.777 & & \\
\hline & $\mathrm{CS} 2$ & 0.791 & & \\
\hline & $\mathrm{CS} 3$ & 0.737 & & \\
\hline & $\mathrm{CS} 4$ & 0.760 & & \\
\hline & CS5 & 0.787 & & \\
\hline \multirow[t]{6}{*}{ Purchase Intention } & & & 0.896 & 0.611 \\
\hline & PI1 & 0.766 & & \\
\hline & PI2 & 0.792 & & \\
\hline & $\mathrm{PI} 3$ & 0.816 & & \\
\hline & PI4 & 0.798 & & \\
\hline & $\mathrm{P} 15$ & 0.809 & & \\
\hline
\end{tabular}

\subsection{Discriminant Validity}

Discriminant validity which is the extent to which a construct is truly distinct from other constructs (Hair et al., 2017) is commonly established using the Fornell-Larcker criterion. Under this criterion, the square root of the AVE values is compared with the latent variable correlations (Hair et al., 2017). However, the commonly-applied Fornell-Larcker criterion has a low sensitivity meaning that discriminant validity problems can sometimes go undetected. Hence, a better approach is used in this study to evaluate the measurement model for discriminant validity which is the Heterotrait-Monotrait Ratio of Correlations (HTMT). Based on the HTMT results tabulated in Table 2, all the values fulfil the criterion of HTMT.95 (Gold et al., 2011) and the HTMT.85 (Kline, 2011). Besides that, the result of the HTMT confidence intervals does not show a value of 1 (Henseler et al., 2015). Overall, the HTMT results proved that all the constructs in the measurement model were achieved based on HTMT inference and also confirms the discriminant validity. 
Table 2. Discriminant validity of the measurement model

\begin{tabular}{llll}
\hline & PI & CS & SQ \\
\hline PI & & & \\
CS & 0.911 & & \\
SQ & 0.737 & 0.830 & \\
\hline
\end{tabular}

Note. $\mathrm{PI}=$ Purchase Intention; $\mathrm{CS}=$ Customer Satisfaction; $\mathrm{SQ}=$ Service Quality.

\subsection{Structural Model Analysis}

The structural model examines the model's predictive capabilities and the hypothesised relationship between exogenous (independent) and endogenous (dependent) variables. The key criteria for assessing the structural model are the significant path coefficient, the level of $R^{2}$ values, the $f^{2}$ effect size and the predictive relevance $Q^{2}$. A Bootstrapping procedure was used to obtain the path coefficient and t-values. Table 3 showed the results for all path coefficients, t-values, and verdict for each hypothesised path.

Table 3. Results of the structural model

\begin{tabular}{llllll}
\hline Relationship & Std. Beta & t-value & Decision & $f^{2}$ & VIF \\
\hline H1: SQ $\rightarrow$ CS & 0.671 & $22.978^{* *}$ & Supported & 0.820 & 1.000 \\
H2: SQ $\rightarrow$ PI & 0.165 & $3.293^{* *}$ & Supported & 0.038 & 1.820 \\
H3: CS $\rightarrow$ PI & 0.659 & $13.676^{* *}$ & Supported & 0.609 & 1.820
\end{tabular}

Note. $\mathrm{p}^{*<0}<0.05 ; * \mathrm{p}<0.01$.

Firstly, the results of collinearity for all indicators showed that VIF values achieved less than 5. Thus, it indicates that there was no problem of collinearity. Secondly, path coefficient was assessing the significance and relevance of the structural model relationships by looking at $\mathrm{t}$-value which is more than 1.96. The results showed that there was a significant relationship between $\mathrm{S} \rightarrow \mathrm{CS}$ (22.978), SQ $\rightarrow$ PI (3.293), and $\mathrm{CS} \rightarrow \mathrm{PI}$ (13.676). Thirdly, the $\mathrm{R}^{2}$ predictive accuracy level for endogenous variable for CS and PI was substantial. Fourthly, the assessment of effect size $\left(f^{2}\right)$ showed that $\mathrm{SQ} \rightarrow \mathrm{CS}$ and $\mathrm{CS} \rightarrow$ PI had a substantial effect size, while SQ $\rightarrow$ PI had a medium effect size. Therefore, all the structural model assessments achieved the PLS-SEM criteria.

\subsection{Mediation Analysis}

The mediation test was run using SmartPLS 3.0 through bootstrapping steps. Step by step of the mediation test was referred to Hair et al. (2017). The mediating test was obtained through "specific indirect effect" result. The tvalues and p-values for H4 showed significant results. The result showed that H4 hypotheses were supported. It was found that the relationship between service quality and purchase intention towards mobile commerce was also mediated by customer satisfaction.

Table 4. Results of the mediation analysis

\begin{tabular}{llllll}
\hline Hypothesis & Relationship & Std. Beta & Std. Error & t-value & p-value \\
\hline H4 & SQ $\rightarrow$ CS $\rightarrow$ PI & 0.443 & 0.036 & 12.284 & $0.000 * *$ \\
\hline
\end{tabular}

Note. $\mathrm{p}^{*}<0.05 ; * \mathrm{p}<0.01$.

\section{Discussion and Conclusion}

The present study aims to give a valuable understanding of the effects of mobile shoppers' satisfaction in mediating the relationship between the service quality and purchase intention towards mobile commerce in Malaysia. The results indicate that there is a significant interrelationship between the constructs. Also, mediating test of satisfaction was successfully and significant. These findings are consistent with earlier research by Mariam et al., (2018), Pauola et al. (2019) as well as Shrawan and Mohit (2018). Therefore, it highlights the importance of mobile shoppers' satisfaction in mediating the relationship between service quality and purchase intention. This study reveals that the eTailQ, as developed by Wolfinbarger and Gilly (2003) is valid for measuring SQ in the context of mobile commerce. It shows that the customer service dimensions have a positive and significant effect 
on overall SQ, CS and PI. In a highly competitive environment, online retailer needs to pay attention to mobile shoppers' intention as it is determined by the SQ. In particular, the online retailer should focus on the customer service at the first priority as it presents the importance of dimensions of SQ to customers. This study has successfully developed an integrated model that links service quality, mobile shoppers' satisfaction, and intention to adopt mobile commerce with one mediator in one framework. The research objectives were met, and all hypotheses were supported. However, the limitation of this study is that it focuses on mobile commerce scope only. Therefore, in future research it is suggested to consider the extension of the scope of the study to otherareas.

\section{References}

Anas, A. M. S., Hartini, A., Faisal, Z., \& Faruq, M. A. (2018). Relationship between system quality, service quality and customer satisfaction: m-commerce in the Jordian context. Journal of Systems and Information Technology, 20(1), 73-102. https://doi.org/10.1108/JSIT-03-2017-0016

Anderson, R. E., \& Srinivasan, S. S. (2003). E-satisfaction and e-loyalty: A contingency framework. Psychology and Marketing, 20(2), 123-138.

Beneke, J., De Sousa, S., Mbuyu, M., \& Wickham, B. (2016). The effect of negative online customer reviews on brand equity and purchase intention of consumer electronics in South Africa. The International Review of Retail, Distribution and Consumer Research, 26(2), 171-201.

Borneo Post. (2018, January 24). Mobile commerce to lead growth in 2018. Retrieved from http://www.theborneopost.com/2018/01/24/mobile-commerce-to-leadgrowth-in-2018/

Cronin, J., Brady, M., \& Hult, G. (2000). Assessing the effects of quality, value and customer satisfaction on behavioural intentions in service environments. Journal of Retailing, 76(2), 193-218.

Enrique, M. A., Karla, B. P. (2019). Precedents of the satisfaction of mobile shoppers. A cross-Country analysis. Electronic Commerce Research and Applications. https://doi.org/10.1016/j.elerap.2019.100919

Ghazali, E., Soon, P. C., Mutum, D. S., \& Nguyen, B. (2017). Health and cosmetics: investigating consumers' values for buying organicpersonal care products. Journal of Retailing and Consumer Services, 39, 154-163. https://doi.org/10.1108/APJML-05-2017-0093.

Gold, A. H., Malhotra, A., \& Segars, A. H. (2011). Knowledge Management: An Organizational Capabilities Perspective. Journal of Management, 18(1), 185-214.

Hair, J. F., Tomas, G. M. H., Ringle, C. M., \& Sarstedt, M. (2017). A Primer on Partial Least Square Structural Equation Modelling (PLS-SEM) (2nd ed.).

Henseler, J., Ringle, C. M., \& Sarstedt, M. (2015). A new criterion for assessing discriminant validity in variance based structural equation modelling. Journal of the Academy of Marketing Science, 43(1), 115-135.

Hsu, C. L., Chen, M. C., Kikuchi, K., \& Machida, I. (2017). Elucidating the determinants of purchase intention toward social shopping sites: a comparative study of Taiwan and Japan. Telematics and Informatics, 34(4), 326-338.

Hussain, R. (2016). The mediating role of customer satisfaction: evidence from the airline industry. Asia Pacific Journal of Marketing and Logistics, 28(2). https://doi.org/10.1108/APJML-01-2015-0001

Kamalul Ariffin, S., Mohan, T., \& Goh, Y. N. (2018). Influence of consumers' perceived risk on consumers' online purchase intention. Journal of Research in Interactive Marketing, 12(3), 309-327.

Karin, B. (2019). Service quality, satisfaction, trust, and loyalty: the moderating role of main-bank and wealth status. International Journal of Bank Marketing, 37(1), 278-302.

Kline, R. B. (2015). Principle and practice of structural equation modeling. Guilford publications.

Krejcie, R. V., \& Morgan, D. W. (1970). Determining sample size for research activities. Educational and Psychological Measurement, 30, 607-610.

Lee, W.I., Cheng, S.Y. and Shih, Y.T. (2017). Effects among product attributes, involvement, word-of- mouth, and purchase intention in online shopping. Asia Pacific Management Review, 22(4), 1-7.

Liu, Y., Li, Q., Tudor, E., Laszlo, J., \& Iliuta C. N. (2019), Mobile shopping platform characteristics as consumer behavior determinants. Asia Pacific Journal of Marketing and Logistics. https://doi.org/10.1108/APJML-05-2019-0308.

Mariam, S., Shahab, A. M., Mansoor, A., \& Asma, S. (2018). Perceptions of fine dining restaurants in Pakistan: what influences customer satisfaction and behavioral intentions? International Journal of Quality \& 
Reliability Management, 35(3), 635-655. https://doi.org/10.1108/IJQRM-07-2016-0113

Markus, B. (2016). E-Service Quality: Development of a Hierarchical Mode. Journal of Retailing, 92(4), 500-517. http://dx.doi.org/10.1016/j.jretai.2016.09.002.

Markus, B., Nivriti, C., Vikas, M., \& Christian, B. (2015). E-Service Quality: A Meta-Analytic Review, Journal of Retailing, 91(4), 679-700. http://dx.doi.org/10.1016/j.jretai.2015.05.004

MIS Asia. (2017). eCommerce Tracker: The Year of the Rooster looks good for Malaysia! Retrieved from http://www.misasia.com/tech/internet/ecommerce-tracker-the-year-of-the-rooster-looksgood formalaysia/

Nguyen, D. P., Nguyen, H. K., \& Angelina, Nhat-Hanh L., (2018). Factors affecting mobile shopping: a Vietnamese perspective. Journal of Asian Business and Economic Studies, 1-20. https://doi.org/10.1108/JABES-05-2018-0012

Parasuraman, A., Zeithaml, V. A., \& Malhotra, A. (2005). ES-QUAL a multiple-item scale for assessing electronic service quality. Journal of Service Research, 7(3), 213-233.

Park, J. H., \& Kim, M. K. (2016). Factors influencing the low usage of smart TV services by the terminal buyers in Korea. Telematics and Informatics, 33(4), 1130-1140.

Paulo, R., Tiago, O., \& Almira, F. (2019). The impact of e-service quality and customer satisfaction on customer behavior in online shopping. Heliyon, 5. https://doi.org/10.1016/j.heliyon.2019.e02690

Rakhi, T. (2018). The role of self-efficacy and customer satisfaction in driving loyalty to the mobile shopping application. International Journal of Retail \& Distribution Management, 46(3), 283-303. https://doi.org/10.1108/IJRDM-11-2016-0214

Shin, D. (2015). Beyond user experience of cloud service: implication for value sensitive approach. Telematics and Informatics, 32(1), 33-44.

Shrawan, K. T \& Mohit, Y. (2018). Predicting online repurchase intentions with e-satisfaction as mediator: a study on Gen Y. VINE Journal of Information and Knowledge Management Systems, 48(3), 427-447. https://doi.org/10.1108/VJIKMS-10-2017-0066

Spiros, G., Sergios, D., \& Vlasis, S. (2010). An examination of the effects of service quality and satisfaction on customers' behavioral intentions in e-shopping. Journal of Services Marketing, 24(2), 142-156. https://doi.org/10.1108/08876041011031118.

Sukanya, K., \& Saroj, K. D. (2015). Impact of trust on the relationship of e-service quality and customer satisfaction. EuroMed Journal of Business, 10(1), 21-46. https:// doi.org/10.1108/EMJB-102013 0053

The Star. (2016). Mobile commerce to continue rapid growth in 2016. Retrieved from: https://www.thestar.com.my:http://www.thestar.com.my/tech/technews/2016/05/20/mobile commerce to-continue rapid-growth-in-2016/

Wolfinbarger, M., \& Gilly, M. (2003). eTailQ: dimensionalising, measuring and predicting etail quality. Journal of Retailing, 79, 183-198. https:// doi.org/10.1016/S0022-4359(03)00034-4.

Wu, P. C., Yeh, G. Y. Y., \& Hsiao, C. R. (2011). The effect of store image and service quality on brand image and purchase intention for private label brands. Australasian Marketing Journal (AMJ), 19(1), 30-39.

Yousef, K., \& Dariyoush, J. (2018). Service quality evaluation and the mediating role of perceived value and customer satisfaction in customer loyalty. International Journal of Tourism Cities, 4(2), 220-244. https://doi.org/10.1108/IJTC-09-2017-0044

Zeithaml, V., Leonard, L., \& Parasuraman, A. (1996). The behavioural consequences of service quality. Journal of Marketing, 60(2), 31-46.

Zeithaml, V., Parasuraman, A., \& Malhotra, A. (2002). Service quality delivery through websites: a critical review of extent knowledge. Journal of Academy of Marketing Science, 30(4), 362-375.

\section{Copyrights}

Copyright for this article is retained by the author(s), with first publication rights granted to the journal.

This is an open-access article distributed under the terms and conditions of the Creative Commons Attribution license (http://creativecommons.org/licenses/by/4.0/). 